\title{
A produção de sentidos sobre a imagem do corpo*
}

Francisco Romão Ferreira ${ }^{1}$

FERREIRA, F.R. The production of meanings regarding body image. Interface - Comunic., Saúde, Educ., v.12, n.26, p.471-83, jul./set. 2008.

This article presents some ways to produce meanings regarding body image from a bibliographic review based on studies by authors in the fields of anthropology, sociology, philosophy, psychology and psychoanalysis. According to these authors, the body is constructed socially and is modeled through social conventions that reproduce the symbolic, cultural or political conflicts of each society. The body materializes the subject vs. society relationship, thereby reflecting the dialogue between biology and symbolism with regard to constructing subjectivity, because subjectivation processes are built in direct relationship with the body. From the authors cited in the text, we will see that sociology, psychology, psychoanalysis or anthropology, singly, do not enable understanding of and/or explanations for the complexity involved in producing meanings regarding the body.

Key words: Body. Subjectivity. Health. Production of meanings.
Apresentam-se algumas formas de produção de sentidos sobre o corpo a partir de uma revisão bibliográfica com base em autores da antropologia, sociologia, filosofia, psicologia e psicanálise. Para esses autores o corpo é construído socialmente, modelado por meio de convenções sociais que vão reproduzir os conflitos simbólicos, culturais ou políticos de cada sociedade. $O$ corpo materializa a relação sujeito $x$ sociedade, refletindo o diálogo entre o biológico e o simbólico na construção da subjetividade, pois os processos de subjetivação são construídos em relação direta com o corpo. Conclui-se que a sociologia, psicologia, psicanálise e antropologia, isoladamente, não dão conta de entender e/ou explicar a complexidade da produção de sentidos sobre o corpo.

Palavras-chave: Corpo. Subjetividade. Saúde. Produção de sentidos.

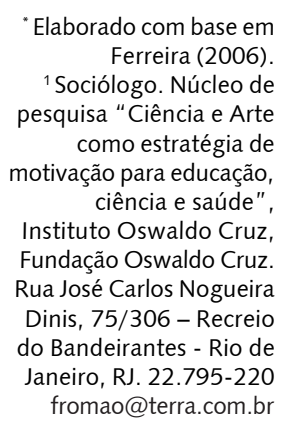

"Elaborado com base em Ferreira (2006). 1 Sociólogo. Núcleo de pesquisa "Ciência e Arte como estratégia de motivação para educação, ciência e saúde", Instituto Oswaldo Cruz, Fundação Oswaldo Cruz. Rua José Carlos Nogueira Dinis, 75/306 - Recreio do Bandeirantes - Rio de Janeiro, RJ. 22.795-220

fromao@terra.com.br 


\section{Introdução}

Este trabalho faz parte de uma pesquisa, iniciada em 2002, e contém trechos da tese de doutorado intitulada "Os sentidos do corpo: cirurgias estéticas, discurso médico e saúde pública", defendida na Escola Nacional de Saúde Pública (Ferreira, 2006), que investigou: a construção de sentidos e valores acerca do corpo, a utilização do discurso científico nessa construção, e a forma como tais sentidos são apropriados e tratados pelos representantes do saber médico.

No decorrer da pesquisa, percebemos que são inúmeras as formas possíveis de se abordar a produção de sentidos sobre o corpo. Trata-se de um tema que, como sabemos, é polêmico, multifacetado, permite diferentes abordagens (às vezes antagônicas), mas sua discussão é fundamental para a formação dos profissionais do campo da saúde. Neste artigo, abordaremos alguns aspectos da construção de sentidos sobre o corpo com base em uma revisão bibliográfica que contempla autores de diferentes campos, tais como: sociologia, antropologia, psicologia e psicanálise. Valendo-nos da apresentação desses autores, podemos perceber que o corpo é socialmente construído e que a sociedade tenta controlar o uso social que se dá aos corpos, reforçando o que é institucionalizado e reproduzindo os conflitos simbólicos de cada cultura.

A tentativa de compreensão da construção de sentidos sobre o corpo não cabe apenas em uma disciplina ou em um modelo rígido de análise. A pluralidade de perspectivas que influenciam tal construção é essencialmente inter ou transdisciplinar, ou melhor, o corpo é essencialmente indisciplinado, ele não cabe em disciplinas rígidas ou limitadoras. Portanto, compreender os sentidos acerca do corpo implica pensá-los com base em uma outra perspectiva, não mais progressiva e linear, mas por saltos e retomadas, enfrentando essa multiplicidade de pontos de vista.

\section{O corpo como um elo de ligação entre o sujeito e o mundo}

A antropologia, desde Marcel Mauss (1872-1950), demonstra a diversidade moral e cultural da humanidade, revelando modos distintos de percepção, utilização e relação com o corpo. Marcas corporais e metamorfoses do corpo são comuns em inúmeras sociedades humanas, tais como: subtração ritual de fragmentos do corpo (clitóris, prepúcio, dentes, dedos, pêlos); modificações na pele (escarificações, incisões, cicatrizes salientes, modelagem de dentes etc); inscrições sob a forma de tatuagens definitivas ou provisórias; maquilagem; modificações na forma do corpo (alongamento do crânio, pescoço, deformação dos pés, deformações no tronco); alongamento do lóbulo das orelhas, lábios, mamilos, formas capilares diferenciadas, ou seja, inúmeros tipos de transformação corporal que atuam como formas de distinção do sujeito na coletividade, utilizando o corpo como objeto de interação e adaptação ao meio social (Mauss, 1950).

O contexto social e cultural modela o corpo em suas diversas maneiras de falar, andar, pular, saltar, dançar, sentar, rir, ficar de pé, dormir, tocar, ver, viver e morrer, ou seja, o indivíduo modela seu corpo no diálogo com a sociedade. As convenções sociais revelam a relação do indivíduo com o seu meio social por meio de: ritos, etiquetas, características gestuais, formas de percepção, de expressão de sentimentos, distinção de classe, códigos culturais e sociais, jogos de aparência, jogos de sedução, erotização, adornos, moda, técnicas corporais, marcas de distinção (como tatuagens e piercings), entretenimento físico, lazer, prazer, sexo, relação com o sofrimento, com a dor etc. Tudo está inscrito no corpo.

Se o corpo é o principal elo de ligação entre o sujeito e o mundo, é ele também que traduz o diálogo "natureza e cultura". O corpo é socialmente construído e nele se materializa a relação sujeito $x$ sociedade, tornando-se a arena onde acontecem os conflitos simbólicos que refletem questões do nosso tempo. A cultura não é apenas um agrupamento de complexos padrões concretos de comportamentos (costumes, tradições, usos, hábitos), mas um conjunto de mecanismos de controle (planos, receitas, regras, instruções), ou o que os engenheiros de computação chamam de "programas" para governar o comportamento. Para Geertz (1989), o homem é precisamente o animal mais desesperadamente dependente de tais mecanismos de controle, extragenéticos, fora da pele, de tais programas culturais, 
para ordenar o seu comportamento. Os padrões culturais agem como sistemas organizados de símbolos, e a cultura, vista como totalidade acumulada de tais padrões, não é apenas um ornamento da existência humana, mas uma condição essencial para ela, a principal base de sua especificidade. A antropologia cultural tem proporcionado recentemente um intenso debate acerca da produção de significados simbólicos sobre o corpo.

Outros setores das Ciências Humanas também estão atentos às formas de construção social dos corpos. A sociologia - e, acima de tudo, a sociologia médica - encorajou os historiadores a tratarem o corpo como a encruzilhada entre o ego e a sociedade (Porter, 2001). Nas tribos urbanas, o corpo tem lugar de destaque, nele são colocados marcas, sentidos e desejos diversos, entre eles, os mais recentes de transformação, adequação e, até mesmo, duplicação. O corpo torna-se, então, a arena onde acontecem discursos e conflitos simbólicos, políticos, culturais, étnicos, históricos, religiosos e econômicos, refletindo as questões do nosso tempo, refletindo também uma sociedade marcada pela valorização do individualismo, narcisismo, hedonismo e consumo. Ele é um dos elementos fundadores da presença do sujeito na sociedade. A construção da identidade está atrelada a ele, e, em alguns casos, a (re)construção do próprio corpo é um dos mecanismos de reconstrução da identidade, da autoestima e do estabelecimento da relação com o mundo. As representações do corpo operam de acordo com as representações disponíveis na sociedade, de acordo com as visões de mundo das diferentes comunidades humanas. O corpo é socialmente construído (Le Breton, 1992).

\section{A imagem do corpo e a construção da identidade}

Para a psicanálise, desde Freud, o Eu é uma extensão da superfície corpórea e sua constituição está diretamente ligada à corporalidade. Os processos fisiológicos e os processos psíquicos são interdependentes, fazendo com que o biológico e o simbólico dialoguem desde o início da construção da subjetividade. As diferenças surgidas na atividade infantil rítmica e repetida que o bebê faz com os lábios ao mamar, com a finalidade de ingerir alimentos, e ao chupar, que é caracterizada pela ausência de uma finalidade biológica, marcam as características da atividade sexual em geral. O bebê não apenas suga o leite da mãe, ele chupa o peito materno. Os lábios do bebê se comportam como uma zona erógena e podem ser considerados como ponto de partida para o estabelecimento do auto-erotismo.

O engolir e o cuspir fazem parte da função alimentar do corpo biológico. A função alimentar pode ser vista, então, como um processo psíquico, fantasmático, do corpo sexual, que toma a atividade biológica como modelo. Pela proposição de Freud, as zonas erógenas são as fontes da pulsão, e a estimulação de tais zonas produzem experiências de satisfação que constituem a base da excitação sexual. No entanto, todo o corpo pode funcionar como zona erógena e qualquer parte do corpo pode ser excitada de maneira autônoma.

A origem deste processo relacional entre o biológico, o psíquico e o ambiente pode ter sua origem anterior mesmo ao nascimento. Segundo Winnicott (1990, p.147), "devemos presumir que, antes do parto, o bebê já seja capaz de reter memórias corporais, pois já existe uma certa quantidade de evidências de que a partir de uma data anterior ao nascimento, nada daquilo que um ser humano vivencia é perdido".

Dessa forma, o processo de construção da psique e do soma tem sua origem nas primeiras experiências de mudança de pressão, temperatura e outros fatores ambientais simples com as quais o feto entra em contato por meio da mãe; sem contar com as experiências emocionais e vivências afetivas intensas vividas pela mãe, gerando a capacidade de reconhecer tais experiências, organizá-las e dar-Ihes valor. No entanto,

[...] neste estágio tão inicial não é lógico pensarmos em termos de um indivíduo, e não apenas devido ao grau de dependência ou apenas porque o indivíduo ainda não está em condições de perceber o ambiente, mas também porque ainda não existe ali um self individual capaz de discriminar o Eu e o não Eu. (Winnicott, 1990, p.153) 
Ou seja, não é possível, nem necessário, estabelecer objetivamente os limites da origem da relação corpo-mente, porém, mesmo no momento anterior à formação do indivíduo consciente, podemos supor que essa relação se manifesta.

No processo de surgimento da consciência individual, essa relação já está presente, mesmo que de forma caótica. A constituição primária da consciência, que é descontínua e atemporal, vai se moldar e criar as condições de desenvolvimento emocional numa tentativa de dar ordem ao caos dominante. Ele (o caos) "[...] se torna significativo exatamente no momento em que já é possível discernir algum tipo de ordem [...] ele já se transformou numa espécie de ordem, um estado que pode se tornar organizado como defesa contra a ansiedade associada à ordem" (Winnicott, 1990, p.157).

No nascimento e nos dias que se seguem, a criança apresenta um esboço do Eu, em virtude das experiências sensoriais realizadas em sua vida intra-uterina, e o contato corporal com a mãe é um fator essencial de seu desenvolvimento afetivo, cognitivo e social na fase adulta. Do mesmo modo, a superfície do conjunto de seu corpo com o de sua mãe pode proporcionar ao bebê experiências tão importantes, por sua qualidade emocional, por sua estimulação da confiança, do prazer e do pensamento, quanto as experiências ligadas à sucção e à secreção. Segundo Didier Anzieu (1989, p.43), "Os cuidados da mãe produzem estimulações involuntárias na epiderme, quando o bebê é banhado, lavado, esfregado, carregado, abraçado. [...] O bebê recebe esses gestos maternos primeiro como uma estimulação e depois como uma comunicação. A massagem se torna uma mensagem".

Por meio dessas interações, vão ser criadas as bases do comportamento psicomotor que serão os precursores dos modelos cognitivos posteriores. Para Winnicott, o rosto da mãe, o holding, o toque, as experiências sensoriais e as reações do círculo humano fornecem o primeiro espelho à criança, que constitui seu Self a partir do que é refletido. Por outro lado, Didier Anzieu evidencia a existência de um equipamento anterior, formado pelas sensações auditivas, que preparam o Self para estruturar as dimensões espacial (orientação e distância) e temporal, de modo que o Self pode ser constituído pela introjeção do universo sonoro (além do gustativo e do olfativo), paralelamente às sensações táteis.

Segundo Anzieu (1989, p.192),

O choro é primeiro pura descarga motora da excitação interna, de acordo com o esquema reflexo que constitui a estrutura primeira do aparelho psíquico. Depois, ele é entendido pelo bebê e pelas pessoas que o cercam como uma exigência e como o primeiro meio de comunicação entre eles, ocasionando a passagem à segunda estrutura do aparelho psíquico onde intervém, em uma reação circular, o sinal, forma primária da comunicação. A via de descarga adquire assim uma função secundária de extrema importância, a de compreensão mútua.

Estas experiências sonoras, gustativas, táteis ou visuais fundamentam o processo psíquico primário que visa à realização alucinatória do desejo e constitui uma primeira forma de simbolização. Há um conhecimento pré-conceitual anterior à linguagem, permitindo que o corpo se constitua e produza conhecimento com base nas primeiras sensações. Assim, a subjetivação é construída numa relação direta com o corpo.

Psique e soma interagem para compreender e, posteriormente, agir no mundo. Dessa forma, a construção do processo perceptivo e cognitivo do sujeito vai estar diretamente ligada à corporalidade. É ela quem fornece os subsídios para a configuração do mundo, a produção de significações e para o estabelecimento de relações objetais. O sujeito age com intencionalidade em relação ao mundo, tentando defini-lo e organizá-lo com base em sua corporalidade. O sujeito organiza, mas não fabrica o mundo, não dá origem a ele e não nega sua materialidade, porém, as representações que ele cria são parte de um processo perceptivo que pode encontrar, no corpo, sua origem.

Para Melanie Klein, a experiência original desta unidade e/ou fragmentação corporal se situa no contexto da "fantasia" (Segal, 1996). Esta fantasia inconsciente é a expressão mental dos instintos (pulsões), e existe, como estes, desde o começo da vida. Estas pulsões necessitam de objetos para se relacionar e se projetar. Para cada pulsão, há uma "fantasia" de um objeto ligado a ela, que vai se adequar à sua necessidade, ou seja, para cada impulso instintivo, há uma fantasia correspondente. Para 
o desejo de comer, corresponde uma fantasia de algo comestível que poderia satisfazer este desejo. É o que Freud descreve como "realização alucinatória dos desejos".

Desde o momento do nascimento, o bebê enfrenta o impacto da realidade, que começa com a própria experiência do nascimento e prossegue com inúmeras experiências de gratificação e frustração de seus desejos. Estas experiências com a realidade influem diretamente na fantasia inconsciente que, por sua vez, também as influencia. A fantasia não é apenas uma fuga da realidade, é uma ferramenta constante e inevitável para enfrentar as experiências reais, em constante interação com elas.

A realidade corporal da criança tem sua estruturação psíquica em relação aos corpos materno e paterno. Depende, porém, primordialmente da existência original das pulsões destrutivas. Para Melanie Klein, esta realidade corporal é fantasmática, pois é por intermédio destas "imagens", que surgem por meio dos desejos violentos de satisfação e destruição, que a criança descobre seu corpo (Segal, 1996). E também por meio do corpo da mãe, ao sugar, morder, apertar, etc. O corpo é vivido pela criança como uma força perigosa. Há uma agressividade original que afeta a realidade fantasmática de seu corpo, do outro e do mundo, ao experimentar a divisão sob tensão de frustração e angústia.

Desde o princípio, há tanto uma tendência de integração como uma tendência de fragmentação, $e$ no decorrer do desenvolvimento, incluindo os primeiros meses, o bebê passa por momentos de integração mais ou menos completa. Porém, quando os processos integradores se fazem mais estáveis e contínuos, surge a "posição depressiva". Melanie Klein definiu esta "posição depressiva" como um momento do desenvolvimento em que o bebê reconhece um objeto total e se relaciona com ele. Quando um bebê reconhece sua mãe, isto significa que ele já a percebe como um objeto total. Ou seja, cada vez mais, o bebê se relaciona não só com o peito, mãos, rosto e os olhos da mãe como objetos diferenciados. Ele começa a perceber a mãe como pessoa total que pode às vezes ser boa, e às vezes ser má, que pode estar às vezes presente e às vezes ausente, e que ele pode amar e odiar ao mesmo tempo.

Este reconhecimento da mãe como uma pessoa total tem muitas conseqüências e abre um mundo de experiências novas. Reconhecer sua mãe como pessoa total significa também reconhecê-la como um indivíduo com vida própria que estabelece e vive relações com outras pessoas. Na medida em que estas experiências se sucedem, o bebê começa a se ver também como uma pessoa independente. A unidade e a fragmentação corporais presentes no adulto correspondem à memória do corpo. Este só é cindido, ou só é sentido como tal, se já sentiu em algum momento esta cisão. As sensações de fragmentação e/ou desamparo só se tornam ameaçadoras na medida em que elas já foram vivenciadas em um outro momento da história daquele sujeito.

O "medo do colapso", a que se refere Winnicott (1994), só é conhecido por quem já o experimentou em algum outro momento e carrega no corpo esta "lembrança". Para ele,

\begin{abstract}
A palavra "colapso" pode ser tomada como significando o fracasso de uma organização de defesa. [...] é um colapso do estabelecimento de um self unitário. O ego organiza defesas contra o colapso da organização. [...] existem momentos em que se precisa dizer a um paciente que o colapso, do qual o medo lhe destrói a vida, já aconteceu. Trata-se de um fato que carrega consigo, escondido no inconsciente. [...] por que o paciente continua a preocupar-se com isso que pertence ao passado? A resposta tem de ser que a experiência original de agonia primitiva não pode cair no passado a menos que o ego possa primeiro reuni-la dentro de sua própria e atual experiência temporal e do controle do onipotente agora. [...] Em outras palavras, o paciente tem que continuar procurando o detalhe passado que não foi experienciado, e esta busca assume a forma de uma procura deste detalhe no futuro. (Winnicott, 1994, p.71-3)
\end{abstract}

Para Anzieu, toda atividade psíquica se estabelece sobre uma função biológica e a pele desempenha um papel fundamental, ela dá limite ao Eu, sendo a base da formação egóica do sujeito. Por meio dela, com base nas primeiras experiências corporais, a criança progressivamente vai criar uma diferenciação entre o mundo interno e o mundo externo, o dentro e o fora, um ambiente no qual ela se sente mergulhada e que lhe traz a experiência de um continente. E a pele é a fronteira que vai delimitar tais 
mundos. Para Anzieu, o "Eu-pele" cria a possibilidade de pensamento, e sua constituição é uma das condições da passagem do narcisismo primário ao narcisismo secundário, e do masoquismo primário ao masoquismo secundário. "Assim como a pele envolve todo o corpo, o Eu-pele visa envolver todo o aparelho psíquico [...] Esta continuidade da casca e do núcleo fundamenta o sentido da continuidade do Self" (Anzieu, 1989, p.115).

Segundo Lacan (1966), no "estádio do espelho", a identificação tem sua origem no período infantil de seis a 18 meses, e consiste numa antecipação da aquisição da unidade funcional do corpo pela criança antes que ela utilize a linguagem. Nesse trabalho, ele apresenta o momento genético de identificação afetiva e de unidade que contribuirá para a formação do Eu; porém, antes de afirmar sua identidade, o Eu se confunde com essa imagem que o forma e o aliena. Essa alienação do sujeito pela imagem é a fonte em que se alimentará a agressividade constitutiva da formação, ao mesmo tempo, do Eu e do vínculo social. "A partir daí, nesse jogo identificatório onde o sujeito "se vê" captado por uma imagem estranha e ao mesmo tempo sua, detectemos justamente a função do processo de projeção, que organiza o modo de percepção do sujeito e confere à realidade sua aparente estabilidade" (Kaufmann, 1996, p.158).

O Estádio do Espelho indica o momento de organização da estrutura do sujeito, tornando clara a referência simbólica que o outro ocupa, o modo como o sujeito, em relação com o outro, regula sua própria imagem (eu ideal), tendo sempre como referência o modelo onipotente do ideal do eu a que o sujeito e o outro estão sujeitos. Esta identificação jamais se tornará completa, não há correspondência possível entre um Eu social e o inconsciente; ela será uma eterna busca por aquele momento em que a criança se volta para o adulto, como que a buscar, de algum modo, seu assentimento. "Captado por uma imagem para sempre inatingível, o sujeito não cessará, a partir de então, de cobrar a explicação disso a esse outro para o qual dirigiu uma primeira vez seu olhar" (Kaufmann, 1996, p.161).

Para Bernard Andrieu, Lacan entende a questão da pele e da formação psíquica do sujeito de forma bem diferente da exposta anteriormente por Didier Anzieu. Enquanto Anzieu vê o Eu-pele como uma construção teórica pela qual o sujeito elabora seu imaginário, representa seu espaço corporal, organiza sua vida mental, seus investimentos libidinais, estabelece um conteúdo psíquico e um continente, distinguindo um dentro e um fora e estabelecendo uma fronteira tanto psíquica quanto somática para o indivíduo, Lacan exclui a imagem libidinal do corpo para promover, por meio do Estádio do Espelho, uma imagem mental do corpo. "Ao invés de considerar a pele como um envelope, ele a considera como o que se encontra no entorno de um buraco" (Andrieu, 2002, p.111).

O envelope fornece a representação de um espaço interior fechado em torno do nosso corpo, o limite psíquico e físico do sentimento de si. O orifício, ao contrário do imaginário do envelope e da superfície, fornece a representação de uma luva que se pode não apenas penetrar como também trocar de lado, se inverter. A relação deixa de ser topográfica e passa a ser topológica. "Sendo assim, a pele se organiza entre o buraco de dentro e o buraco de fora" (Andrieu, 2002, p.112). Para Lacan, o ego é uma figuração imaginária da consciência, é o que articula este espaço topológico do corpo em linguagem.

O Eu é uma forma de totalidade que tenta dar conta da falta originária, do furo, que é passagem de significantes e de fluxos com o mundo, uma espécie de representação mental da imagem do corpo na construção da identidade, e sempre vai haver algo da realidade que não está representado na imagem do corpo. Há sempre algo da ordem do corpo que não se deixa representar, toda idéia de totalidade deixa algo do lado de fora. Para interagir com a cultura, tenho de aderir a uma identidade exterior e preciso abrir mão de parte da sexualidade e da agressividade. Sendo assim, a identidade, para ser reconhecida, precisa do reconhecimento do outro, e o corpo, ao invés de ser agente, passa a ser objeto da cultura. Neste processo de construção da identidade, a imagem corporal assume o papel de principal veículo da identificação. Pois por intermédio desta identificação o sujeito se constitui e se transforma, assimilando ou se apropriando, em momentos-chave de sua evolução, dos aspectos, atributos ou traços dos seres humanos que o cercam (Roudinesco, Plon, 1998, p.363).

A "imagem do corpo" (nos planos fisiológico, psicológico ou social) incorpora sentidos diferentes e pode ser compreendida com base em leituras distintas, como veremos a seguir. Ela não é mera sensação ou imaginação, é a forma como se estrutura em nossa mente a relação com o próprio corpo e 
com o mundo, imprimindo, no inconsciente, contribuições anatômicas, fisiológicas, neurológicas, psicológicas, sociológicas etc.

A insatisfação com esta imagem pode levar à dismorfobia, que é uma síndrome psicopatológica que produz a não aceitação do próprio corpo e, freqüentemente, conduz o portador a procurar um cirurgião plástico, solicitando solução cirúrgica para um defeito que o paciente julga ter. Essa obsessão com a aparência física ilustra um fenômeno reconhecido atualmente como uma categoria diagnóstica da psiquiatria, o Transtorno Dismórfico Corporal (TDC), que traduz uma preocupação exagerada com um defeito mínimo ou imaginário na aparência física, trazendo sofrimento significativo ou prejuízo em áreas importantes da vida do indivíduo (Monteiro, 2003).

Em termos clínicos, a expressão "imagem do corpo" foi utilizada por Paul Schilder (médico, psiquiatra e filósofo), em 1923, para designar, ao mesmo tempo, as representações conscientes e inconscientes da posição do corpo no espaço, considerando-se três aspectos: o de um suporte fisiológico, o de uma estrutura libidinal e o de uma significação social. O termo foi inspirado na noção de esquema corporal proposto pelo neurologista inglês Henry Haed (1861-1940). A formação interdisciplinar de Schilder (1886-1940), que articula fenomenologia, psicologia da Gestalt e psicanálise, permite analisar a formação da imagem que cada um tem de si próprio na articulação da realidade biológica do corpo com sua realidade erógena e sua projeção no mundo, realizando um estudo minucioso acerca da imagem corporal e do problema psicológico da relação entre as impressões de nossos sentidos, nossos movimentos, nossa motilidade em geral em sua relação com o Outro (Shilder, 1994).

Segundo ele, postura corporal, percepção, emoção e personalidade se confundem na experiência psicossomática, existindo sempre uma personalidade que experimenta uma percepção mediada por uma emoção. Somos seres emocionais, personalidades que se revelam na ação, somos narcisistas e amamos nosso corpo. Sendo assim, a topografia do modelo postural do corpo será a base das atitudes emocionais para com o corpo. Nosso conhecimento dependerá das correntes eróticas que fluem através do nosso corpo e também as influenciará.

As zonas eróticas desempenharão um papel particular no modelo postural do corpo (Shilder, 1994). Desse modo, as impressões provenientes da postura corporal desempenham importante papel na construção do conhecimento do nosso corpo, mas se confundem também com a estrutura erógena e libidinal, com o suporte biológico e fisiológico, com a projeção da imagem corporal no meio social, a expressão das emoções, a imitação e as identificações e sua relação com o que é considerado Belo. Desta forma, podemos tomar de empréstimo partes do corpo de outra pessoa e incorporá-las à nossa imagem corporal (personalização). Mas também podemos nos identificar com a personalidade de outras pessoas, e isto pode levar a uma atenção e atitude particulares em relação a partes do nosso corpo.

Sem se referir a Schilder, Françoise Dolto (1908-1988) retoma o termo "imagem do corpo" para designar a "encarnação simbólica do inconsciente do sujeito desejante", ou seja, uma representação inconsciente do corpo, distinta do esquema corporal, que seria sua representação consciente ou préconsciente. Segundo ela, o esquema corporal faz parte de uma forma de percepção neurobiológica que é a mesma para todos. Já a imagem do corpo é específica para cada um, pois está ligada ao sujeito, sua história e sua relação com o mundo. Ela é eminentemente inconsciente, suporte do narcisismo e encarnação simbólica do sujeito desejante.

As imagens que a pessoa faz do próprio corpo são a síntese viva de suas experiências emocionais vividas através das sensações erógenas eletivas, arcaicas ou atuais, sendo também memória inconsciente de todo o vivido relacional. É na imagem do corpo que o tempo se cruza com o espaço e que o passado inconsciente ressoa na relação presente. Para ela,

[...] o esquema corporal, que é a abstração de uma vivência do corpo nas três dimensões da realidade, estrutura-se pela aprendizagem e pela experiência, ao passo que a imagem do corpo se estrutura pela comunicação entre sujeitos e o vestígio, no dia-a-dia, memorizado, do gozar frustrado, reprimido ou proibido (castração, no sentido psicanalítico, do desejo na realidade). (Dolto, 2001, p.15) 
Nos trabalhos de Freud, estão presentes os pressupostos de que o corpo é a fonte básica de toda experiência mental. Ele afirma que não existe descontinuidade na vida mental, nada acontece por acaso (muito menos os processos mentais), existindo sempre uma causa para cada pensamento, sentimento ou ação, e que nos desejos e no corpo ficam rastros dessa "memória" (Freud, 1977). Esses rastros se cristalizam com o tempo, que, para Freud, é descontínuo e não obedece à racionalidade. Para ele, existem conexões entre todos os eventos mentais. Desse modo, todos os eventos possuem um "espaço" no inconsciente e podem ser acessados a qualquer momento. Nele se localizam elementos que nunca foram conscientes e que não são acessíveis à consciência. São materiais que foram "excluídos" da consciência, censurados e reprimidos. Mas esse material não é esquecido ou perdido, apenas não é permitido que seja lembrado. Quando o inconsciente libera memórias para o consciente, essas memórias não perderam nada de sua força emocional, pois os processos mentais inconscientes são atemporais e sua estruturação não é racionalizável.

A energia pulsional necessária para administrar as tensões internas obedece às suas próprias leis, portanto, na relação com o corpo e sua "imagem", se materializam desejos e processos mentais que obedecem à sua lógica interna. Esta energia pulsional se manifesta por meio de processos nos quais a energia libidinal disponível na psique é vinculada ou investida na representação mental de uma pessoa, idéia ou coisa. Freud utiliza o termo "catexia", que traduz justamente este processo de investimento. Este conceito é criado para instrumentalizar a teoria psicanalítica, que está interessada em compreender onde a libido foi catexizada inadequadamente para poder liberá-la ou redirecioná-la, já que a identificação e a canalização da energia psíquica são fundamentais para a compreensão do sujeito na busca de uma possível administração de conflitos e acordos psíquicos.

\section{Os usos sociais do corpo}

$\mathrm{Na}$ relação sujeito $\mathrm{x}$ sociedade, existem interesses e necessidades (conscientes e inconscientes) tanto do sujeito, como, também, os interesses e estratégias de controle da ordem social. Os códigos de conduta, os interditos e os padrões de comportamento aceitos e valorizados socialmente influenciam o comportamento dos sujeitos com relação aos seus corpos. Como foi dito anteriormente, trata-se de uma relação topológica, não havendo o dentro e o fora. Um influencia o outro simultaneamente.

O corpo também é visto como submisso à ordem política e social e objeto de dominação identificado com o capitalismo, que impõe sua dominação moral e material sobre os usos sociais do corpo, favorecendo a alienação e fazendo da ordem política uma ordem social dos corpos. Para JeanMarie Brohm (1975), toda ordem política se impõe pela violência, coerção e constrangimento sobre o corpo, de modo que ordem política e ordem social se mesclam ao fazer do corpo seu campo de batalha (Le Breton, 1992).

Para Boltanski (1979), o uso social do corpo é determinado pelas condutas físicas dos sujeitos sociais, regulados por uma cultura somática que traduz as condições objetivas da ordem cultural. Para ele, a percepção da doença, o recurso ao médico, o consumo de medicamentos, os meios materiais de existência, as condições de existência e a difusão do conhecimento médico vão impor ao corpo um uso adequado aos interesses do sistema produtivo. Utilizando indicadores como hábitos alimentares, relação com a dor, sentidos corporais e critérios de beleza, ele delimita os usos sociais do corpo nas diferentes classes sociais.

Na obra La distinction, de 1979, Pierre Bourdieu amplia e torna mais preciso este pensamento que entende o uso social do corpo como objetivação do gosto de classe. Os hábitos corporais corresponderiam ao conjunto de condutas próprias de comportamentos ligados a uma posição de classe, sendo os hábitos sociais e gostos culturais inscritos num comportamento próprio que funcionaria como uma forma de distinção social.

Mas esse controle exercido pela sociedade sobre o corpo não se dá unicamente atendendo aos interesses ideológicos. As estratégias e os interesses são variados. Há uma multiplicidade de processos, de origens diferentes, que se reproduzem e se distinguem, fazendo da construção da imagem do corpo, hoje, não apenas uma forma de controle social que se manifesta diretamente, mas algo que atua na produção de subjetividade e, também, na montagem de uma estratégia de mercado pronto a 
atender aos desejos de metamorfose corporal. Os interesses individualistas e narcisistas dos sujeitos vão ao encontro dos interesses dos empresários e profissionais responsáveis pela "indústria da metamorfose".

Ao falar sobre a dominação e o controle disciplinar dos corpos, Michel Foucault (1987) afirma que

\begin{abstract}
[...] em qualquer sociedade, o corpo está preso no interior de poderes muito apertados, que Ihe impõem limitações, proibições ou obrigações. [...] Forma-se então uma política das coerções que são um trabalho sobre o corpo, uma manipulação calculada de seus elementos, de seus gestos, de seus comportamentos. O corpo humano entra numa maquinaria de poder que o esquadrinha, o desarticula e o recompõe. (Foucault, 1987, p.119)
\end{abstract}

Entretanto, o corpo escapa às determinações e tentativas de controle impostas pelo poder, que, por sua vez, também se metamorfoseia, se adapta, criando novas formas de repressão e controle.

Onde antes havia um controle moral, médico ou exploração econômica, hoje há uma erotização que se coloca como uma nova forma de investimento e tentativa de controle sobre o corpo. Segundo ele, "Como resposta à revolta ao corpo, encontramos um novo investimento que não tem mais a forma de controle-repressão, mas de controle-estimulação: "fique nu, [...] mas seja magro, bonito, bronzeado!" (Foucault, 1984, p.147).

Após vencer várias barreiras na estrutura do poder, as mulheres conquistaram liberdade, postos de destaque e reconhecimento, tanto em termos legais como profissionais, mas ao mesmo tempo tornaram-se vítimas dessa ditadura da beleza, magreza e juventude; vítimas, também, dos distúrbios relacionados à alimentação, dos cuidados obsessivos com o corpo e com a aparência, da necessidade de corresponder a um modelo idealizado de beleza que é estabelecido socialmente, fazendo com que as conquistas das últimas décadas sejam ofuscadas pela luta inglória contra a balança e o tempo. Velhice e obesidade são motivos para estigmatização.

Essas tiranias (da beleza, da magreza e da juventude) estão entre as novas formas de controle disciplinar sobre o corpo. Há um emaranhado de relações que atravessa diferentes instituições e interesses, criando novas tentativas de assujeitamento e controle sobre o corpo por meio da moda, da publicidade, do culto ao corpo, ao dietético e à performance esportiva ou social. Não se trata mais de um controle disciplinar do social por meio de aparelhos repressivos, mas de uma variedade de formas de sedução que fazem da beleza e da juventude o novo conceito que dá sentido ao estatuto do corpo. Para Gilles Lipowetsky, o vestuário foi substituído pela ditadura da magreza e da juventude.

A ansiedade que domina as mulheres quando estão gordas ou com celulite mostra essa tirania. Antes, as filhas sonhavam em ser parecidas com as mães, queriam usar roupas parecidas. Hoje, acontece exatamente o contrário, as mães é que desejam ter a aparência mais jovem. Estar em forma e não envelhecer é a obsessão número um de hoje (Lipowetsky, 2002).

\title{
A produção da subjetividade relativa ao corpo
}

Para Gilles Deleuze, o corpo não se deixa controlar, ele escapa às tentativas de apreensão e aprisionamento pelos saberes estabelecidos. Segundo ele, o corpo é linguagem. Mas ele pode ocultar a palavra que é, pode encobri-la (Deleuze, 1998). Ou seja, o corpo oculta suas verdadeiras intenções e desejos, ele encerra uma linguagem escondida, própria, abstrata, que vai se traduzir em atos que alguns poderiam chamar de perversões, mas que podem ser vistos também como "hesitação objetiva do corpo" (Deleuze, 1998, p.290), não sujeição, afirmação de uma vontade própria e legítima. Como se houvesse um "corpo sem órgãos" que interagisse com o organismo e o sistema motor e que, às vezes, se opusesse a ele, insatisfeito com aquele conjunto de válvulas, represas, comportas, taças ou vasos comunicantes que não passam de produção fantasmática objetificada, materializada em partes do corpo.

O organismo teria apenas a função de atuar como

[...] fenômeno de acumulação, coagulação, sedimentação que lhe impõe formas, funções, ligacões, organizações dominantes e hierarquizadas, transcendências organizadas para 
extrair um trabalho útil [...] o Corpo sem órgãos é o campo da imanência do desejo, o plano de consistência própria do desejo (ali onde o desejo se define como processo de produção, sem referência a qualquer instância exterior). (Deleuze, 1996, p.15)

Ou seja, por mais que a sociedade coloque entraves, barreiras ou formas de cercear a atuação do sujeito, a incapacidade de controlar o corpo faz dele um rebelde que não se deixa aprisionar ou que, pelo menos, subverte a tentativa de controle que vem do mundo exterior.

Para Guattari (1992), devemos pensar a produção de subjetividade relativa ao corpo como uma produção que envolve instâncias individuais, coletivas e institucionais. E o seu entendimento não se limita a nenhuma disciplina ou instância dominante de determinação que guie as outras instâncias numa causalidade unívoca. Neste sentido, a sociologia, a antropologia, a psicologia, a psicanálise ou a semiologia isoladamente não dão conta de entender e/ou explicar a complexidade de sua (re)produção, não havendo também um pólo único de produção de sentidos, nem uma única forma de produção ou apropriação do que é produzido. As disciplinas se revelam limitadas para dar conta da complexidade e da multiplicidade de abordagens acerca do corpo, ele extrapola as disciplinas, não se deixa aprisionar por nenhuma delas.

Esta abordagem da subjetividade nos distancia, cada vez mais, das abordagens acadêmicas clássicas, que privilegiam a construção do conhecimento com base em uma única disciplina tornada a detentora das possibilidades discursivas de entendimento da questão; e nos aproxima do que Guattari chama de Agenciamentos coletivos de enunciação, proposto no livro Caosmose - um novo paradigma estético, no qual ele define a subjetividade como um conjunto de condições e relações que torna possível o surgimento de uma nova forma de pensar que pode ser auto-referencial, individual, mas também pode ser produzida socialmente, fazendo com que a identidade e a alteridade assumam uma mesma postura, obedeçam às mesmas instâncias individuais e/ou coletivas de produção de desejos e sentidos. Tal produção de sentido tanto pode ir de encontro como ao encontro da lógica predominante nas sociedades capitalistas, que tenta bloquear processos de singularização e instaurar processos de individualização.

A produção de sentidos sobre a imagem do corpo e a percepção que o sujeito tem do próprio corpo é, ao mesmo tempo, individual e coletiva, opera no social, mas não se limita a ele. Ela se desenvolve para além do indivíduo, das relações interpessoais ou dos complexos intrafamiliares, mesclando intensidades pré-verbais, afetos e códigos sociais de conduta. Para Guattari (1992, p.20), "a subjetividade não é fabricada apenas através das fases psicogenéticas da psicanálise ou dos 'matemas do inconsciente', mas também nas grandes máquinas sociais, mass-midiáticas, lingüísticas, que não podem ser chamadas de humanas". Desta forma, os aparatos conceituais das disciplinas das ciências humanas se mostram insuficientes quando tomados isoladamente.

O capitalismo é visto como uma máquina de produção de sentidos que engendra papéis, desejos, pontos de vista, corporalidades e padrões estéticos variados, utilizando-se de comportamentos que tanto se prestam à submissão como à libertação. A subjetividade dessa máquina se instaura em universos de virtualidade que ultrapassam a territorialidade existencial em todos os sentidos. Tal ordem é projetada na realidade do mundo e na realidade psíquica e produz os modos de relações humanas até em suas representações inconscientes. Ela se manifesta nas relações pessoais, nos códigos de conduta, nas formas de trabalhar, amar, gozar, falar, vestir, nos cuidados com o corpo, com a forma do corpo, com a produção de sentidos e de afetos, nos esquemas de conduta, de ação, de gestos, de pensamento, de sentido, de sentimento etc. "Ela incide nas montagens da percepção, da memorização, ela incide na modelização das instâncias intra-subjetivas - instâncias que a psicanálise reifica nas categorias de ego, superego, ideal do ego, enfim, naquela parafernália toda" (Guattari, 1999, p.42).

Essa forma de produção de subjetividade não só atua individualmente emitindo estímulos diretamente ao inconsciente, produzindo indivíduos normalizados, submetidos a um sistema hierárquico de valores e expostos à submissão, como também atua na produção de uma subjetividade social, que se manifesta na produção e no consumo, produzindo inclusive nossos sonhos, nossas paixões, nossos desejos, referências de mundo e projetos de vida. As máquinas de produção de subjetividade não se reduzem a modelos de identidade familiares ou do meio social e cultural, mas atuam também nos 
${ }^{2}$ Reificação - conceito marxista que define $o$ ato (ou resultado do ato) de transformação das propriedades, relações e ações humanas em propriedades, relações e ações de coisas produzidas pelo homem, que se tornam independentes (e que são imaginadas como originalmente independentes) do homem e governam sua vida. Significa igualmente a transformação de seres humanos em seres semelhantes a coisas, que não se comportam de forma humana, mas de acordo com as leis do mundo das coisas. (Bottomore, 1988)

${ }^{3}$ Fetichismo - Marx diz que, na sociedade capitalista, os objetos materiais possuem certas características que lhe são conferidas pelas relações sociais dominantes, mas que aparecem como se Ihes pertencessem naturalmente. A analogia é feita com a religião, na qual as pessoas conferem a alguma entidade um poder imaginário. Só que não são propriedades naturais. São sociais.

Constituem forças reais, não controladas pelos seres humanos e que, na verdade, exercem controle sobre eles; são as formas de aparência objetivas das relações econômicas que definem o capitalismo (Bottomore, 1988) mecanismos de controle social, nos afetos particulares, nos processos cognitivos e interativos e nas instâncias psíquicas que definem as maneiras de perceber o mundo. As formas de construção da identidade, percepção do próprio corpo e construção de um modelo ideal de referência com base em padrões socialmente definidos não escapa a essa lógica, ou seja, a subjetividade é essencialmente fabricada e modelada no registro do social (Guattari, 1999), e os cuidados com o corpo e com a saúde estão no centro deste processo maquínico.

Essa produção de subjetividade acerca do corpo é construída socialmente articulando estímulos variados, fazendo com que o indivíduo atue não apenas como consumidor dos produtos, serviços e desejos, mas também como produtor desse universo de desejos, colocando o próprio corpo como objeto reificado ${ }^{2}$, mercadoria símbolo, tornado ele, também, um produto de consumo devidamente inscrito na órbita do fetiche ${ }^{3}$ da mercadoria, colocado na hierarquia dos objetos de consumo cotidiano.

A construção da individualidade e da singularidade também dialogam com essa tentativa de cooptação, de adequação aos modelos dominantes de individualização (vista aqui como adequação às normas e valores dominantes) e singularização (vista como tentativa de produção original), produzindo às vezes uma pseudosingularização, que tem como referência modelos pré-fabricados de singularidade. Tornando, assim, muito mais difícil escapar a essa lógica social.

Uma mulher que voluntariamente não segue o padrão hegemônico, não se preocupa com a dieta, que não pinta seus primeiros cabelos brancos ou que não segue o modelo dominante pode ser discriminada e sofrer as sanções cabíveis em função da sua "rebeldia". Não lutar contra a passagem do tempo passa a ser crime inafiançável, e a tentativa de escapar da individualização e produzir uma singularização nunca é indolor. A imagem que ela tem do próprio corpo é atravessada por sentidos que estão além do seu controle, e a tentativa de criar uma imagem singular esbarra na barreira imposta pela institucionalização das condutas.

O corpo ocupa, assim, um lugar de destaque no processo de diferenciação progressiva e hierarquizada da vida social. A "imagem do corpo" se torna uma forma de capital que define e é definida pelo meio social, por intermédio dela se produzem novos códigos e se reproduzem antigos códigos de valorização e status. Suas possibilidades estéticas permitem transitar por diferentes posições na hierarquia social, alterando e definindo trajetórias afetivas, pessoais, profissionais ou sociais, criando novos espaços na ordem social e produzindo novas formas de distinção social.

A variedade de alterações corporais (corretivas ou estéticas) às quais o corpo está sujeito hoje, a ampliação do mercado ligado ao culto ao corpo e à sua transformação, e a valorização de parâmetros estéticos, como definidores das condições de saúde e da concepção do que venha a ser "saudável", nos colocam diante de diferentes questões na área da saúde que suscitam novas formas de entendimento. Sendo assim, este trabalho pretende contribuir para o debate acerca dos sentidos dados ao corpo no conjunto da sociedade, destacando a impossibilidade de compreensão deste processo com base em uma única disciplina, e ressaltando que o corpo se encontra nessa encruzilhada entre o ego e a sociedade, entre a natureza e a cultura, entre o biológico e o simbólico.

A pluralidade de perspectivas que influenciam a construção de sentidos sobre a imagem do corpo é inter e transdisciplinar, envolvendo instâncias psíquicas, individuais, coletivas, culturais, sociais, simbólicas, institucionais, religiosas etc. $\bigcirc$ desenvolvimento da biotecnociência, o crescimento dos mercados relativos às transformações corporais de natureza estética, a popularização das cirurgias 
plásticas e os problemas ocorridos neste setor colocam as diferentes formas de construção da imagem do corpo, a estetização da saúde (entendida, aqui, como a valorização de parâmetros estéticos como definidores das condições de saúde) e as tentativas de metamorfose corporal (por meio de cirurgias, implantes, próteses, tratamentos, medicamentos, práticas esportivas, marcas corporais etc.) como novas questões de saúde pública a serem discutidas e enfrentadas.

\section{Referências}

ANDRIEU, B. La nouvelle philosophie du corps. Paris: Érès, 2002.

ANZIEU, D. O Eu-pele. São Paulo: Casa do Psicólogo, 1989.

BOLTANSKI, L. As classes sociais e o corpo. Rio de Janeiro: Graal, 1979.

BOTTOMORE, T. Dicionário do pensamento marxista. Rio de Janeiro: Zahar, 1988.

BOURDIEU, P. La distinction: critique sociale de jugement. Paris: Minuit, 1979.

BROHM, J-M. Corps et politique. Paris: Delarge,1975.

DELEUZE, G. Lógica do sentido. São Paulo: Perspectiva, 1998.

DELEUZE, G.; GUATTARI, F. Mil platôs: capitalismo e esquizofrenia. Rio de Janeiro: Ed. 34, 1996. v.3.

DOLTO, F. A imagem inconsciente do corpo. São Paulo: Perspectiva, 2001.

FERREIRA, F.R. Os sentidos do corpo: cirurgias plásticas, discurso médico e Saúde Pública. 2006. Tese (doutorado) - Escola Nacional de Saúde Pública, Rio de Janeiro. 2006.

FOUCAULT, M. Vigiar e punir. Petrópolis: Vozes, 1987.

Microfísica do poder. Rio de Janeiro: Graal, 1984.

FREUD, S. O ego e o id. Rio de Janeiro: Imago, 1977.

GEERTZ, C. A interpretação das culturas. Rio de Janeiro: LTC, 1989.

GIL, J. No pain, no gain. O corpo mutante do bodypiercing. Cad. Subjetividade, v.5, n.2, p.267-83, 1997.

GUATTARI, F. Caosmose: um novo paradigma estético. Rio de Janeiro: Ed. 34, 1992.

GUATTARI, F.; ROLNIK, S. Micropolítica: cartografias do desejo. Petrópolis: Vozes, 1999.

KAUFMANN, P. Dicionário enciclopédico de psicanálise: o legado de Freud e Lacan. Rio de Janeiro: Zahar, 1996.

LACAN, J. Écrits 1. Paris: Éditions du Seuil, 1966.

LE BRETON, D. La sociologie du corps. Paris: Presses Universitaires de France, 1992.

LIPOVETSKY, G. Beleza para todos. Entrevista concedida a Silvia Rogar. Rev. Veja, edição 1770, p.5-11, 25 de setembro de 2002.

MAUSS, M. Les techniques du corps. Paris: PUF, 1950. 
MONTEIRO, A.C. Espelho, espelho meu ...: percepção corporal e caracterização nosográfica no Transtorno Dismórfico Corporal. 2003. Dissertação (Mestrado) - Escola Nacional de Saúde Pública, Rio de Janeiro. 2003.

PORTER, R. História do corpo. In: BURKE, P. A escrita da história: novas perspectivas. São Paulo: Unesp, 2001. p.31-57.

ROUDINESCO, E.; PLON, M. Dicionário de psicanálise. Rio de Janeiro: Zahar, 1998.

SEGAL, H. Introducción a la obra de Melanie Klein. Buenos Aires: Paidós, 1996.

SHILDER, P. A imagem do corpo. São Paulo: Martins Fontes, 1994.

WINNICOTT, D.W. Explorações psicanalíticas. Porto Alegre: Ciências Médicas, 1994.

Natureza humana. Rio de Janeiro: Imago, 1990.

FERREIRA, F.R. La producción de sentidos sobre la imagen del cuerpo. Interface Comunic., Saúde, Educ., v.12, n.26, p.471-83, jul./set. 2008.

Se presentan algunas formas de producción de sentidos sobre el cuerpo a partir de una revisión bibliográfica con base en autores de antropología, sociología, filosofía, psicología y psicoanálisis. Para estos autores, el cuerpo se construye socialmente, modelado por medio de convenciones sociales que van a reproducir los conflictos simbólicos, culturales o políticos de cada sociedad. El cuerpo materializa la relación sujeto - sociedad, reflejando el diálogo entre lo biológico y lo simbólico en la construcción de la subjetividad, pues los procesos de subjetividad se construyen en relación directa con el cuerpo. Conclúyese que la sociología, la psicología, el psicoanálisis y la antropología, aisladamente, no bastan para entender y/o explicar la complejidad de la producción de sentidos sobre el cuerpo.

Palabras clave: Cuerpo. Subjetividad. Salud. Producción de sentidos.

Recebido em 30/08/07. Aprovado em 16/05/08 
K 